\title{
Electrochemical Studies for Cation Recognition with Diazo-Coupled Calix[4]arenes
}

\author{
Bongsu Kim and Tae Hyun Kim \\ Department of Chemistry, Soonchunhyang University, Asan 336-746, Republic of Korea \\ Correspondence should be addressed to Tae Hyun Kim; thkim@sch.ac.kr
}

Received 2 October 2014; Revised 19 December 2014; Accepted 2 January 2015

Academic Editor: Bengi Uslu

Copyright (C) 2015 B. Kim and T. H. Kim. This is an open access article distributed under the Creative Commons Attribution License, which permits unrestricted use, distribution, and reproduction in any medium, provided the original work is properly cited.

The electrochemical properties of diazophenylcalix[4]arenes bearing ortho-carboxyl group (o-CAC) and ortho-ester group (o$\mathrm{EAC})$, respectively, in the presence of various metal ions were investigated by voltammetry in $\mathrm{CH}_{3} \mathrm{CN} . o$-CAC and $o$-EAC showed voltammetric changes toward divalent metal ions and no significant changes with monovalent alkali metal ions. However, $o$ CAC preferentially binds with alkaline earth and transition metal ions, whereas no significant changes in voltammetric signals are observed in $o$-EAC with alkaline earth metal ions. $o$-EAC only binds with other transition metal ions. This can be explained on metal ion complexation-induced release of proton from the azophenol to the quinone-hydrazone tautomer followed by internal complexation of the metal ion with aid of nitrogen atoms and ortho-carbonyl groups in the diazophenylazocalix[4]arenes.

\section{Introduction}

Macrocyclic receptors have been synthesized and received much attention to be endowed with superior molecular recognition properties used in chemical sensors $[1,2]$. Calixarenes have been extensively used as macrocyclic hosts for a wide range of metal ions because they have unique structure of conformational adaptability toward hosting guests along with easy derivatization of the lower rim and upper rim and the possibility of locking a desired conformation (cone, partial cone, 1,2-alternate, and 1,3-alternate) [1,3,4]. Many have been utilized as optical sensors to monitor the target by UV/Vis and fluorescence spectroscopic measurements. Among them, azocalixarene bearing azophenol units acting as a chromogenic center are particularly attractive for their interesting aspects of complexation with alkali, alkaline earth, and transition metal ions disclosed by studying the optical behavior of chromophoric units [4-8]. Our group has been also interested in designing selective optical sensors toward metal ions based on azocalixarene derivatives $[9,10]$. As one of our efforts, we have developed a simple qualitative analysis protocol to screen alkali, alkaline earth, and transition metal ions using azocalix[4]arene derivatives. To tune up the selectivity toward specific metal ions, we have also tried to perform the $\mathrm{pH}$ study of azocalix[4]arene bearing carboxyl group and to change the position or the numbers of substituents, which leads to enhancement of the selectivity for $\mathrm{Pb}^{2+}, \mathrm{Cu}^{2+}$, or $\mathrm{Ca}^{2+}$ metal ions in the spectroscopic measurements.

Azophenols as electroactive groups in azocalixarene system can be studied by also electrochemical measurements [11-13]. Electrochemical sensors are quite interesting and useful because electrochemical changes such as current and voltage by recognition of guest molecule can be directly and immediately reported to electrical signal, which is not necessary to use other transducers. Thus, electrochemical techniques are suitable for the development of convenient, sensitive, selective, and low cost devices that could be utilized for a rapid monitoring, ultimately applicable to hand-held operation. However, only a few examples of electrochemical measurements using azocalix[4]arenes have been reported [10, 14-16]. Previously, our group reported colorimetric discrimination system towards alkali, alkaline earth, and transition metal ions using azophenylcalix[4]arenes bearing ortho-carboxyl group (o-CAC) and ortho-ester group (oEAC) (Scheme 1) [9]. To the best of my knowledge, however, 

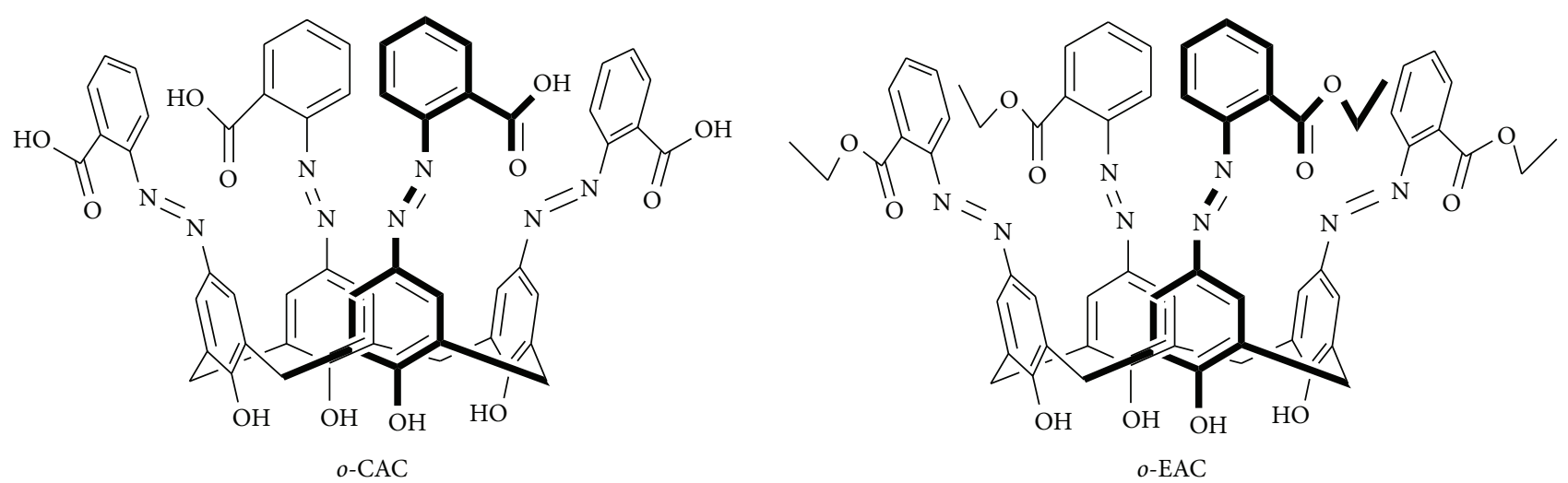

SCHEme 1: Structures of ortho-carboxyl azocalix[4] arene (o-CAC) and ortho-ester azocalix[4] arene (o-EAC).

voltammetric study of $o$-CAC and $o$-EAC has not been reported. Present study reports $o$-CAC exhibiting a selective response to alkaline earth and transition metal ions and $o$-EAC to transition metal ions in acetonitrile solution $\left(\mathrm{CH}_{3} \mathrm{CN}\right)$ by electrochemical methods. One can discriminate almost all metal ions by simple electroanalytical methods.

\section{Experimental}

2.1. Synthesis. Synthesis and identification of $o-C A C$ or $o-$ EAC were described in the previous papers [9].

2.1.1. 5,11,17,23-Tetra[(2-ethyl acetoethoxyphenyl) (azo)phenyl] calix[4]arene (o-EAC). A solution of 2-aminobenzoate $(3.10 \mathrm{~g}, 18.7 \mathrm{mmol}), \mathrm{NaNO}_{2}(1.46 \mathrm{~g}, 21.1 \mathrm{mmol})$, and concentrated $\mathrm{HCl}(5 \mathrm{~mL})$ in water $(10 \mathrm{~mL})$ was added dropwise over a period of about 15 minutes into a solution of calix[4] arene $(2.00 \mathrm{~g}, 4.70 \mathrm{mmol})$ in THF : pyridine $(5: 2)$ $(25 \mathrm{~mL})$ at $0{ }^{\circ} \mathrm{C}$. The solution was stirred for $15 \mathrm{~min}$ and then for additional $24 \mathrm{hrs}$ at room temperature. After removal of the solvent in vacuo, the resulting solid was dissolved in EtOAc $(100 \mathrm{~mL})$ and the organic layer was washed three times with water. The organic layer was dried over anhydrous $\mathrm{MgSO}_{4}$ and the solvent was removed in vacuo to give a reddish oil. Column chromatography using EtOAc: hexane (2:1) provided $2.4 \mathrm{~g}(45 \%)$ of $\mathbf{1}$ as a yellow orange solid. Mp: $158-162^{\circ} \mathrm{C}$. IR (KBr pellet, $\left.\mathrm{cm}^{-1}\right): 3220,1735 .{ }^{1} \mathrm{H}$ NMR $\left(200 \mathrm{MHz}, \mathrm{CDCl}_{3}\right): \delta 7.43-7.22(\mathrm{~m}, 24 \mathrm{H}, \mathrm{Ar}-\mathrm{H}), 4.24(\mathrm{~d}$, $\left.4 \mathrm{H}, \mathrm{Ar}-\mathrm{CH}_{2}-\mathrm{Ar}\right), 3.97-3.86\left(\mathrm{~m}, 8 \mathrm{H}, \mathrm{COCH}_{2} \mathrm{CH}_{3}, J=6.9\right.$, $7.3 \& 6.7 \mathrm{~Hz}), 3.42\left(\mathrm{~d}, 4 \mathrm{H}, \mathrm{Ar}-\mathrm{CH}_{2}-\mathrm{Ar}\right), 0.82-0.75(\mathrm{t}, 12 \mathrm{H}$, $\mathrm{COCH}_{2} \mathrm{CH}_{3}, J=6.9 \mathrm{~Hz}$ ). ${ }^{13} \mathrm{C}$ NMR (DMSO-d 6 ): $\delta 168.1$, 159.2, 151.5, 145.3, 132.3, 130.8, 129.7, 129.6, 129.0, 124.5, 119.7, 61.5, 32.3, 14.8. FAB MS $m / z\left(\mathrm{M}^{+}\right)$: Calcd., 1129.18. Found. 1129.0. Anal. Calcd. for $\mathrm{C}_{64} \mathrm{H}_{56} \mathrm{~N}_{8} \mathrm{O}_{12}$ : C, 68.07; H, 5.00. Found: C, 68.05; H, 5.02 .

2.1.2. 5,11,17,23-Tetra[(2-benzoic acid)(azo)phenyl]calix[4] arene $(o-C A C)$. A solution of $o$-EAC $(0.44 \mathrm{mmol})$ and $\mathrm{NaOH}(4.42 \mathrm{mmol})$ in ethanol $(10 \mathrm{~mL})$ and water $(5 \mathrm{~mL})$ was refluxed for $12 \mathrm{~h}$ and evaporated in vacuo. The residue was dissolved in ethyl acetate and the solution was washed twice with $20 \% \mathrm{HCl}$ and then three times with water. The organic layer was dried over $\mathrm{MgSO}_{4}$ and evaporated in vacuo to yield $0.35 \mathrm{~g}(78 \%)$ of $o$-CAC as a red solid. Mp: $164-168^{\circ} \mathrm{C}$, IR ( $\mathrm{KBr}$ pellet, $\left.\mathrm{cm}^{-1}\right): 3220,1735 .{ }^{1} \mathrm{H}$ NMR $\left(200 \mathrm{MHz}\right.$, DMSO- $\left.\mathrm{d}_{6}\right): \delta$ $10.25(4 \mathrm{H}, \mathrm{s},-\mathrm{OH}), 7.33-7.02$ (m, 24H, Ar- $H$ ), 4.24 (broad s, $4 \mathrm{H}, \mathrm{Ar}-\mathrm{CH}_{2}-\mathrm{Ar}$ ), 3.42 (broad s, $4 \mathrm{H}, \mathrm{Ar}-\mathrm{CH}_{2}-\mathrm{Ar}$ ). ${ }^{13} \mathrm{C}$ NMR $\left(\right.$ DMSO-d $\left.{ }_{6}\right): \delta 30.6,116.8,122.4,130.1,130.4,130.9$, 134.5, 146.1, 154.5, 155.3, and 169.7. FAB MS $m / z\left(\mathrm{M}^{+}\right)$: Calcd. 1016.28. Found. 1016.96. Anal. Calcd. For $\mathrm{C}_{56} \mathrm{H}_{40} \mathrm{~N}_{8} \mathrm{O}_{12}$ : C, 66.14; H, 3.96; N, 11.02; O, 18.88. Found: C, 66.13; H, 3.94; N, 11.03 ; O, 18.89.

2.2. Electrochemical Measurements. Electrochemical measurements were carried out with a Model 660D electrochemical workstation ( $\mathrm{CH}$ Instruments, Austin, TX, USA). The three-electrode system consists of a glassy carbon working electrode, an $\mathrm{Ag} / \mathrm{Ag}^{+}$(in $0.1 \mathrm{M} \mathrm{AgNO}_{3}$ ) reference electrode, and a Pt wire counter electrode. The surface of the working electrode was polished with 0.03 and $0.05 \mu \mathrm{m}$ alumina (CH Instruments, Austin, TX, USA) and rinsed with deionized water. Residual alumina particles were thoroughly removed by positioning the electrode in an ultrasonic bath for $10 \mathrm{~min}$. Then, the electrode was dried and washed with pure acetonitrile before use. The supporting electrolyte was $0.1 \mathrm{M}$ tetrabutylammonium hexafluorophosphate $\left(\mathrm{TBAPF}_{6}\right)$ in $\mathrm{CH}_{3} \mathrm{CN}$. The concentration of $o$-CAC or $o$-EAC was $0.1 \mathrm{mM}$ and stock solution of metal perchlorate salts with various concentrations was prepared using acetonitrile. Test solutions were prepared by placing $2 \mathrm{~mL}$ of the $o$-CAC or $o$ EAC solution into an electrochemical cell, adding appropriate aliquot of each metal stock solution with a microsyringe. All experiments were carried out in a nitrogen atmosphere at room temperature. All reagents were purchased from Aldrich and used without further purification.

\section{Results and Discussion}

The voltammetric behavior of $o$-CAC or $o$-EAC is complicated because the reductions of the azo groups of $o$-CAC or $o$-EAC produce highly proton-sensitive intermediates so that azophenol itself acts as a proton source. The reductions of the azo groups involve two electrons and, however, if a proton source is rich enough to cleave the azo linkage 


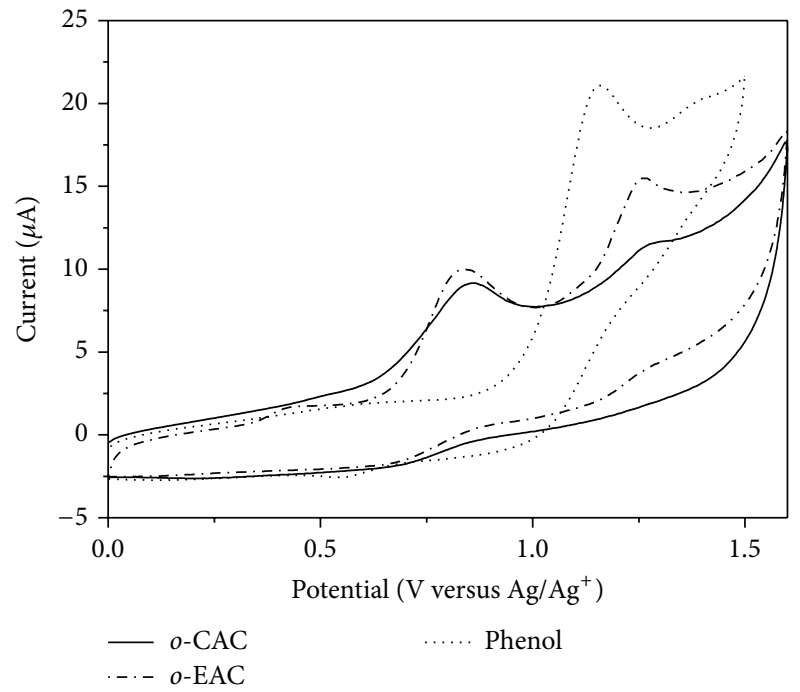

(a)

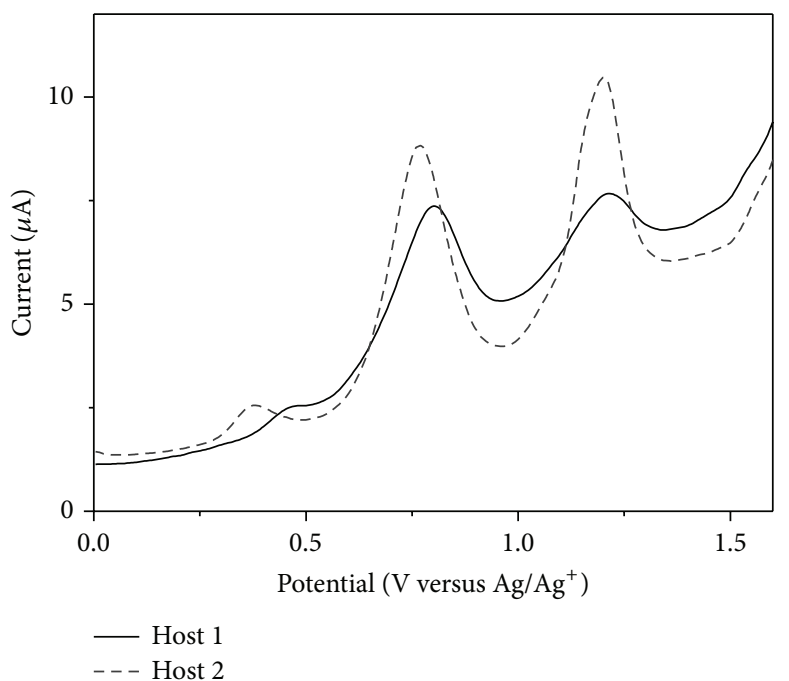

(b)

Figure 1: (a) Cyclic voltammograms $(\mathrm{CVs})$ of $o$-CAC, $o$-EAC $\left(1 \times 10^{-4} \mathrm{M}\right)$, and phenol $\left(5 \times 10^{-4} \mathrm{M}\right)$ in $0.1 \mathrm{M} \mathrm{TBAPF}_{6} / \mathrm{CH}_{3} \mathrm{CN}_{\text {. Scan }}$ rate: $50 \mathrm{mV} / \mathrm{s}$. (b) Differential pulse voltammograms (DPVs) of $o$-CAC and $o$-EAC $\left(1 \times 10^{-4} \mathrm{M}\right)$ in $0.1 \mathrm{M} \mathrm{TBAPF}_{6} / \mathrm{CH}_{3} \mathrm{CN}$. Pulse amplitude: $50 \mathrm{mV}$.

to two $-\mathrm{NH}_{2}$ during the electrochemical reduction process, cyclic voltammogram $(\mathrm{CV})$ will give irreversible redox peaks involving four electrons all together [17]. On the other hand, the oxidation of phenol in $\mathrm{CH}_{3} \mathrm{CN}$ shows only one oxidation peak, as shown in Figure 1(a).

Thus, more attention has been paid to the oxidation wave rather than reduction waves of $o$-CAC or $o$-EAC. Electrochemical properties of $o$-CAC or $o$-EAC were also investigated by voltammetry at glassy carbon electrode in $0.1 \mathrm{M}$ $\mathrm{TBAPF}_{6} / \mathrm{CH}_{3} \mathrm{CN}$, by taking advantage of the phenol moieties present at the lower rim. Electrochemistry of $o$-CAC or $o$ EAC based on the oxidation of phenols is different from that of phenol (Figure 1(a)). Phenol exhibits simple redox behavior so that an irreversible electron transfer process is observed as one oxidation peak around $1.2 \mathrm{~V}$ and calix[4] arene with only phenol functional groups also shows one irreversible oxidation peak [18]. Based on the electrochemistry of phenol, $o$-CAC or $o$-EAC is also expected to be oxidized around $1.2 \mathrm{~V}$. Differently from our prediction, $o$-CAC or $o$-EAC shows two irreversible oxidation waves (Figure 1(a)). This result can be proved by the fact that $o$-CAC or $o$-EAC presents a mixture of the two tautomeric forms, namely, azophenol and quinone-hydrazone, as explained in previous papers by spectroscopic data of $o$-CAC or $o$-EAC $[9,10]$. Phenol groups of calixarene with only phenol group are identical because it forms intramolecular hydrogen bonding array in the lower rim of calixarene. But in this case, intramolecular hydrogen bonding array distorts and even breaks by the tautomerization of $o$-CAC or $o$-EAC. Therefore, $o$-CAC or $o$-EAC shows two irreversible peaks at intervals. One peak is due to the ease of protonation of phenol and the other peak is due to the difficulty of oxidation of phenol by intramolecular hydrogen bonding. In order to get a better resolution, differential pulse voltammetry of $o$-CAC or $o$-EAC was also performed
TABLE 1: Anodic peak potentials of $o$-CAC and $o$-EAC.

\begin{tabular}{lcccc}
\hline & \multicolumn{2}{c}{$o$-CAC } & \multicolumn{2}{c}{$o$-EAC } \\
& CV & DPV & CV & DPV \\
\hline$E_{\text {pre }}$ & - & 460 & 424 & 376 \\
$E_{p 1}$ & 861 & 804 & 840 & 776 \\
$E_{p 2}$ & 1277 & 1212 & 1262 & 1204 \\
$\Delta E_{p}$ & & & & \\
$\left(=E_{p 2}-E_{p 1}\right)$ & 416 & 408 & 422 & 428 \\
\hline
\end{tabular}

in the same condition of cyclic voltammetry. As shown in Figure 1(b), there are two irreversible waves and prewave in the oxidation process of both hosts, which is thought to be due to the tautomerization. Anodic potential of $o$-CAC and $o$-EAC is summarized in Table 1 . The potential differences between two peaks $\left(\Delta E_{p}=E_{p 2}-E_{p 1}\right)$ of $o$-CAC and $o$-EAC are around $400 \mathrm{mV}$. These values reflect the strength of intramolecular hydrogen bonding. $\Delta E_{p} \mathrm{~s}$ of $o$-CAC from both $\mathrm{CV}$ and differential pulse voltammogram (DPV) are slightly smaller than those of $o$-EAC. This might be due to relatively longer distance between two oxygens of $o$-CAC than that of $o$ EAC caused by the relative degree of steric hindrance between $o$-carboxyl groups and $o$-ester groups.

The complexation behavior of $o$-CAC and $o$-EAC was also investigated in the presence of alkali, alkaline earth, and transition metal ions in $\mathrm{CH}_{3} \mathrm{CN}$ by comparing the voltammetric behaviors of their phenols in differential pulse voltammetry with $0.1 \mathrm{M} \mathrm{TBAPF}_{6}$ as the supporting electrolyte. A constant volume $(10 \mu \mathrm{L})$ of each cation stock solution was injected successively into the electrochemical solution to make 0.5-1.5 equivalent of cation in the solution. DPVs were recorded after 


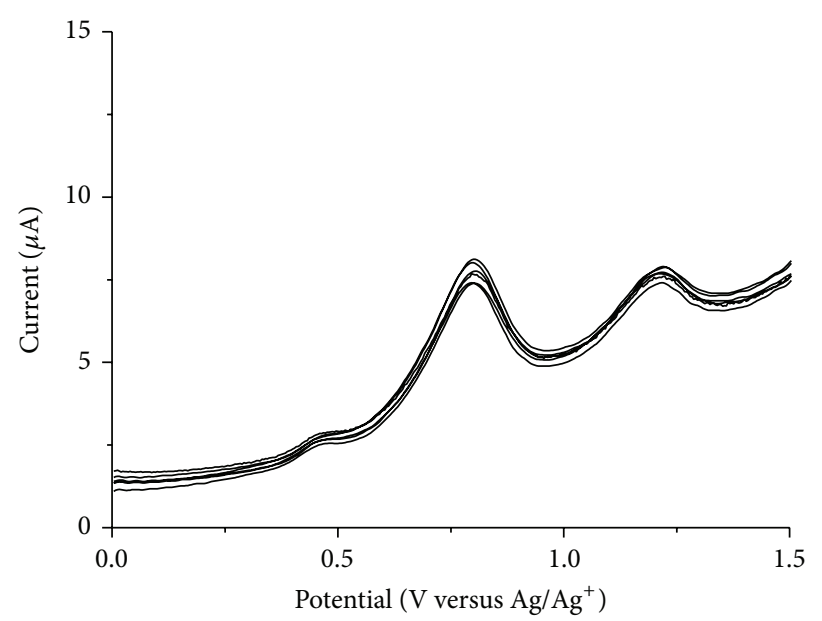

(a)

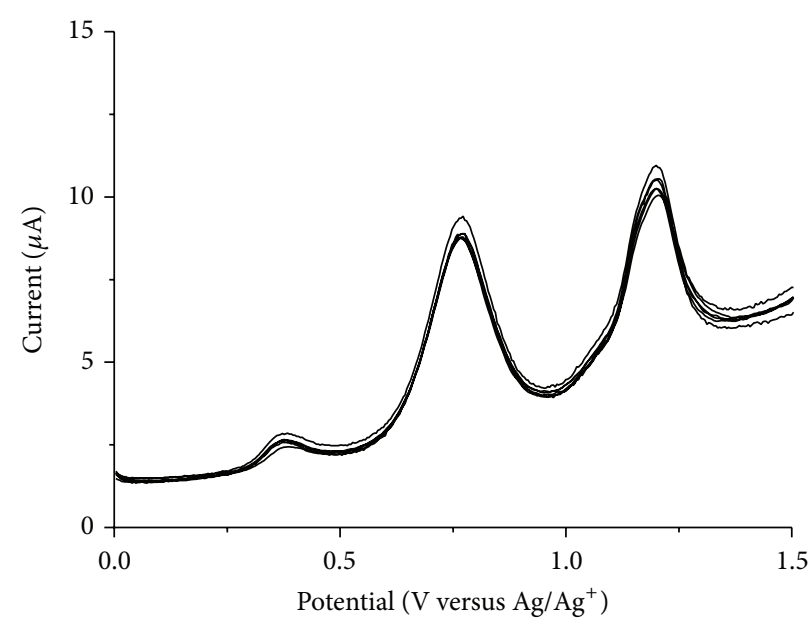

(b)

Figure 2: DPVs of (a) $o$-CAC and (b) $o$-EAC $\left(1 \times 10^{-4} \mathrm{M}\right)$ in the absence and presence of alkali metal ions $\left(1 \times 10^{-4} \mathrm{M}\right)$.



(a)



(b)

Figure 3: DPVs of (a) $o$-CAC and (b) $o$-EAC $\left(1 \times 10^{-4} \mathrm{M}\right)$ in the absence and presence of alkaline earth metal ions $\left(1 \times 10^{-4} \mathrm{M}\right)$.

adding stoichiometric equivalent of metal ions successively to the respective electrochemical solution. DPVs of $0.1 \mathrm{mM} o-$ $\mathrm{CAC}$ and $o$-EAC in the presence of one equivalent of alkali and alkaline earth metal ions are shown in Figures 2-5.

Successive addition of an alkali metal ion to $o$-CAC or $o$-EAC, which is incapable of encapsulation, caused no significant change in the peak current or potential in accordance with previous spectroscopic data [9]. Figure 2 shows typical DPVs of $o$-CAC and $o$-EAC with the addition of one equivalent of alkali metal ions.

Very similar results are observed with $o$-EAC-alkaline earth metal complexation (Figure 3(b)). On the other hand, $o$-CAC in the presence of alkaline earth metal ions shows changes in peak currents and peak potentials (Figure 3(a)).
Preoxidation wave around $0.5 \mathrm{~V}$ disappears and first oxidation peak shifts at more negative potential (Figure 3(a)). The presence of transition metal ions also alters both the oxidation peak potentials and currents of $o$-CAC or $o$-EAC, as in the voltammetric behavior of $o$-CAC-alkaline earth cation complexation (Figure 4). This result indicates that there is a subtle balance between metal complexation-induced release of proton from the azophenol to the quinone-hydrazone tautomer, and the ortho-carboxyl groups of o-CAC or ortho-ester groups of $o$-EAC can stabilize the quinone-hydrazone form in azocalix[4]arene after adding alkaline earth or transition metal ions.

The peak potential differences between $o$-CAC or $o$-EAC and $o$-CAC- or $o$-EAC-metal ion complexes are summarized 


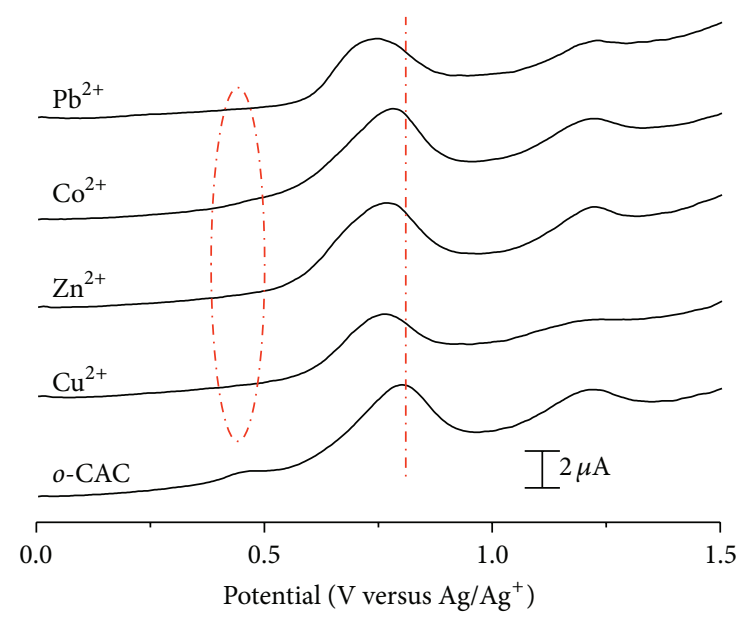

(a)

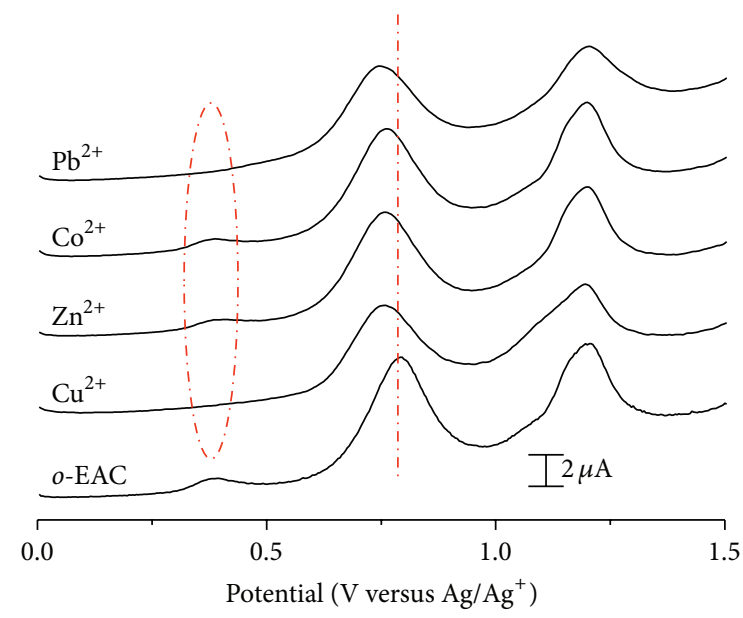

(c)

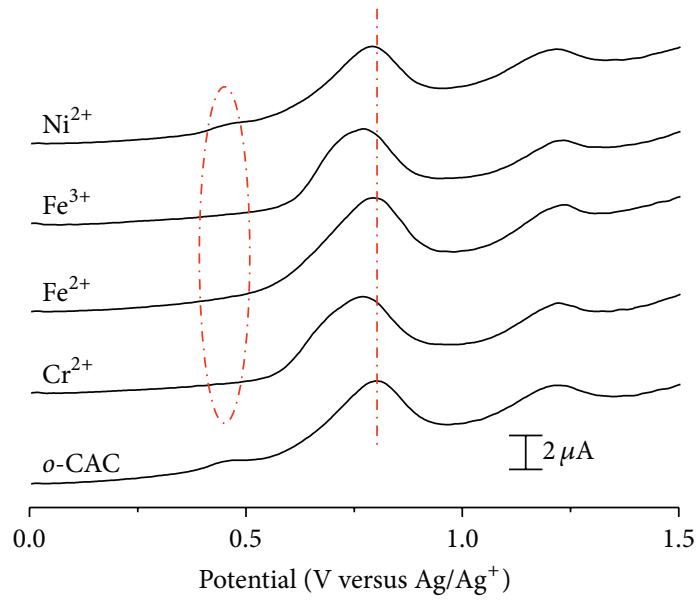

(b)

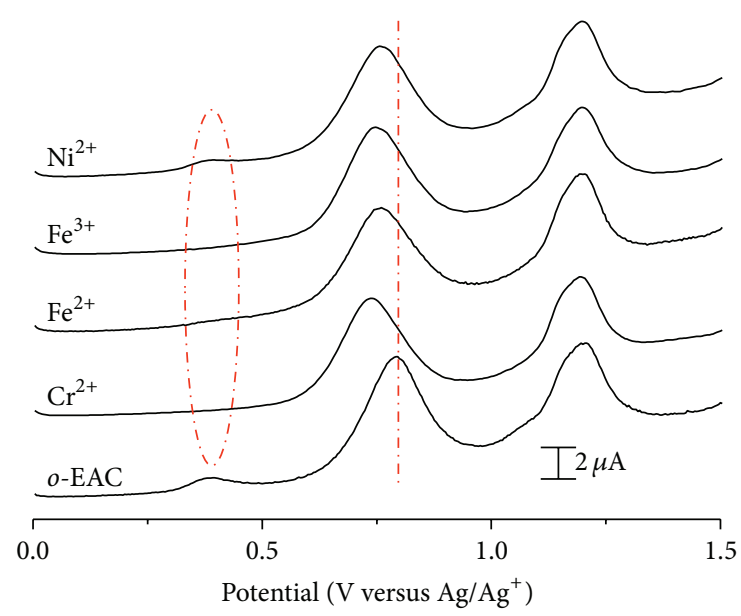

(d)

Figure 4: DPVs of $((\mathrm{a}),(\mathrm{b})) o$-CAC $\left(1 \times 10^{-4} \mathrm{M}\right)$ and $((\mathrm{c}),(\mathrm{d})) o$-EAC $\left(1 \times 10^{-4} \mathrm{M}\right)$ in the absence and presence of transition metal ions $(1 \times$ $\left.10^{-4} \mathrm{M}\right)$. Pulse amplitude: $50 \mathrm{mV}$, pulse width: $0.05 \mathrm{sec}$, sample width: $0.0167 \mathrm{sec}$, and pulse period: $0.2 \mathrm{sec}$.

TABle 2: Anodic peak potential differences between $o$-CAC or $o$-EAC and $o$-CAC- or $o$-EAC-metal ion complexes in DPVs.

\begin{tabular}{ccccccccccccccccccc}
\hline \multicolumn{2}{c}{$\mathrm{mV}$} & $\mathrm{Li}^{+}$ & $\mathrm{Na}^{+}$ & $\mathrm{K}^{+}$ & $\mathrm{Rb}^{+}$ & $\mathrm{Cs}^{+}$ & $\mathrm{Mg}^{2+}$ & $\mathrm{Ca}^{2+}$ & $\mathrm{Sr}^{2+}$ & $\mathrm{Ba}^{2+}$ & $\mathrm{Cu}^{2+}$ & $\mathrm{Zn}^{2+}$ & $\mathrm{Co}^{2+}$ & $\mathrm{Pb}^{2+}$ & $\mathrm{Cr}^{2+}$ & $\mathrm{Fe}^{2+}$ & $\mathrm{Fe}^{3+}$ & $\mathrm{Ni}^{2+}$ \\
\hline \multirow{2}{*}{ o-CAC } & $\Delta E_{p 1}$ & -4 & 0 & -8 & 0 & -4 & -32 & -44 & -40 & -44 & -40 & -36 & -20 & -56 & -32 & -8 & -32 & -12 \\
& $\Delta E_{p 2}$ & 12 & 4 & 4 & 4 & 8 & 12 & 16 & 16 & 16 & 4 & 12 & 12 & 20 & 12 & 24 & 24 & 8 \\
\hline \multirow{2}{*}{ o-EAC } & $\Delta E_{p 1}$ & -4 & -8 & -12 & -8 & -4 & -20 & -12 & -12 & -12 & -16 & -20 & -12 & -28 & -36 & -16 & -28 & -20 \\
& $\Delta E_{p 2}$ & -4 & 0 & -4 & -4 & -4 & -4 & 0 & -4 & -4 & -8 & -4 & -4 & 0 & -8 & 0 & -4 & -4 \\
\hline
\end{tabular}

in Table 2. The presence of alkaline earth and transition metal ions affects the oxidation peak potentials of $o$-CAC, and transition metal ions influence the oxidation behavior of $o$-EAC, whereas all alkali metal ions lead to no noticeable change in the voltammetric behavior of $o$-CAC and $o$-EAC. This result is in good agreement with previous spectroscopic experiments [9].

In order to confirm this electrochemical recognition phenomenon, the electroactivities of $o$-CAC or $o$-EAC were measured in the presence of increasing substoichiometric amount of $\mathrm{Sr}^{2+}, \mathrm{Zn}^{2+}$, or $\mathrm{Cr}^{2+}$ cations, as representative models of alkaline earth or transition metal ions. The behavior observed in the oxidation process is shown in Figure 5. With a function of concentration of metal ion, preoxidation waves around $0.5 \mathrm{~V}$ of both $o$-CAC and $o$-EAC disappear and first oxidation peaks shift at more negative potential. While second oxidation peak of both $o$-CAC and $o$-EAC decreases, first oxidation peak of $o$-EAC, however, increases and $o$-CAC 


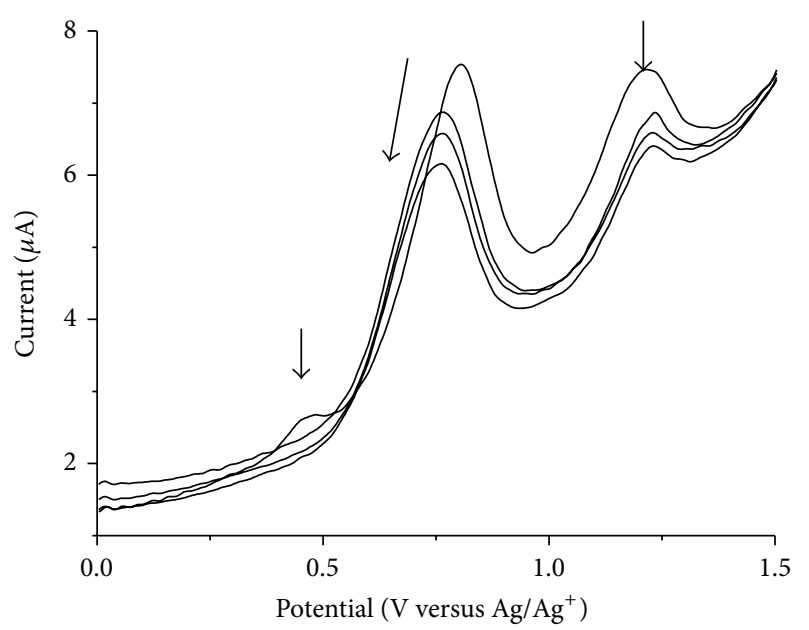

(a)

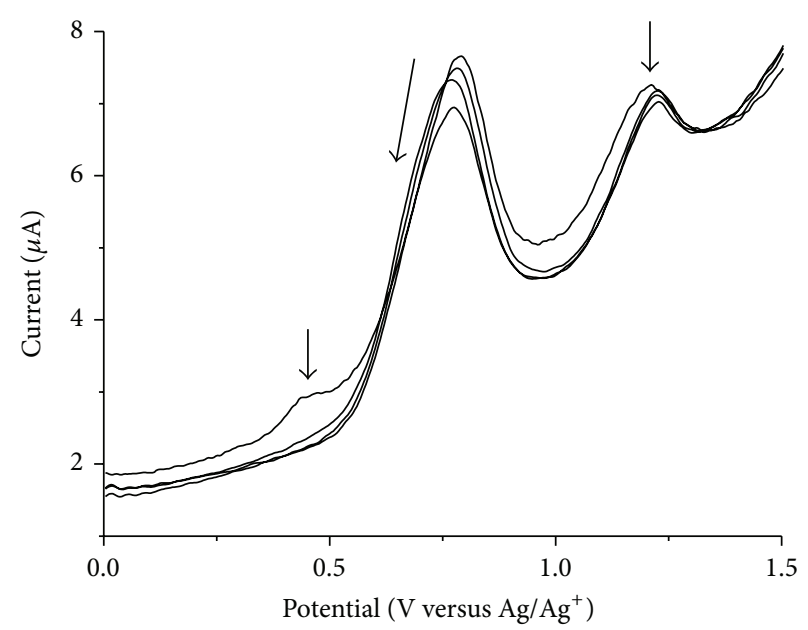

(b)



(c)

Figure 5: DPVs of $o$-CAC $\left(1 \times 10^{-4} \mathrm{M}\right)$ upon the addition of increasing amount of (a) $\mathrm{Sr}^{2+}$ and (b) $\mathrm{Zn}^{2+}$, and (c) DPVs of $o$-EAC upon the addition of increasing amount of $\mathrm{Cr}^{2+} .\left[\mathrm{M}^{2+}\right]=0.5,1.0$, and $1.5 \times 10^{-4} \mathrm{M}$. Pulse amplitude: $50 \mathrm{mV}$, pulse width: $0.05 \mathrm{sec}$, sample width: $0.0167 \mathrm{sec}$, and pulse period: $0.2 \mathrm{sec}$.

decreases. This implies the metal complexation-induced release of protons from the azophenol to the quinonehydrazone tautomer, but the tautomerization to the quinonehydrazone becomes somewhat faster in $o$-EAC and slower in $o$-CAC, as the concentration of metal ions increases. From this, the possible complexation mechanism based on the $1: 1$ complexation is proposed in Scheme 2.

\section{Conclusion}

The electrochemical behaviors of azocalix[4]arene derivatives containing ortho-carboxyl or diethyl ester groups have been investigated in the absence and the presence of alkali, alkaline earth, and transition metal ions by electrochemical measurements. $o$-CAC with the ortho-carboxyl groups preferentially binds with alkaline earth and transition metal ions over alkali metal ions, whereas $o$-EAC with the orthodiethyl ester groups shows selective complexation properties toward transition metal ions over alkali and alkaline earth metal ions. The complexation of metal ions gives rise to negative shifts of first oxidation peaks in the electrochemistry of the azocalix[4]arenes. This may be attributed to the metal complexation-induced release of protons from the azophenol to the quinone-hydrazone tautomer. With this system, one can screen metal ions to alkali, alkaline earth, and transition metal ions using simple electrochemical methods.

\section{Conflict of Interests}

The authors declare that there is no conflict of interests regarding the publication of this paper. 




SCHeme 2: Possible complexation mechanism of $o$-CAC and $o$-EAC with metal ion.

\section{Acknowledgment}

This work was supported by the Soonchunhyang University Research Fund.

\section{References}

[1] F. Davis and S. A. Higson, Macrocycles: Construction, Chemistry, and Nanotechnology Applications, John Wiley \& Sons, Hoboken, NJ, USA, 2011.

[2] Y.-W. Yang, Y.-L. Sun, and N. Song, "Switchable host-guest systems on surfaces," Accounts of Chemical Research, vol. 47, no. 7, pp. 1950-1960, 2014.

[3] J. Vicens, J. M. Harrowfield, and L. Baklouti, Calixarenes in the Nanoworld, Springer, Dordrecht, The Netherlands, 2007.

[4] C. D. Gutsche, Calixarenes: An introduction, Monographs in Supramolecular Cemistry, Royal Society of Chemistry (Great Britain), Cambridge, UK, 2nd edition, 2008.

[5] O. Aleksiuk, S. Cohen, and S. E. Biali, "Selective hydroxyl replacement in calixarenes: amino-, azo-, and xanthenocalixarene derivatives," Journal of the American Chemical Society, vol. 117, no. 38, pp. 9645-9652, 1995.

[6] H. Deligöz, "Azocalixarenes: synthesis, characterization, complexation, extraction, absorption properties and thermal behaviours," Journal of Inclusion Phenomena and Macrocyclic Chemistry, vol. 55, no. 3-4, pp. 197-218, 2006.

[7] L. L. Lu, S. F. Zhu, X. Z. Liu, Z. Z. Xie, and X. Yan, "Highly selective chromogenic ionophores for the recognition of chromium(III) based on a water-soluble azocalixarene derivative," Analytica Chimica Acta, vol. 535, no. 1-2, pp. 183187, 2005.
[8] F. Oueslati, I. Dumazet-Bonnamour, and R. Lamartine, "Synthesis and extraction properties of multifunctionalized azocalix[4]arenes containing bipyridyl subunits," New Journal of Chemistry, vol. 28, no. 12, pp. 1575-1578, 2004.

[9] T. H. Kim, S. H. Kim, L. Van Tan, Y. Dong, H. Kim, and J. S. Kim, "Diazo-coupled calix[4]arenes for qualitative analytical screening of metal ions," Talanta, vol. 74, no. 5, pp. 1654-1658, 2008.

[10] T. H. Kim, J. S. Kim, and H. Kim, "Spectrophotometric and electrochemical study of $\mathrm{Cu}^{2+}$-selective azocalix 4 arene bearing p-carboxyl group," Bulletin of the Korean Chemical Society, vol. 34, no. 11, pp. 3377-3380, 2013.

[11] H. Hou, F. Vacandio, M. L. di Vona, and P. Knauth, "Electropolymerization of sulfonated phenol by cyclic voltammetry," Journal of Applied Polymer Science, vol. 129, no. 3, pp. 1151-1156, 2013.

[12] J. Obirai, F. Bedioui, and T. Nyokong, "Electro-oxidation of phenol and its derivatives on poly-Ni(OH)TPhPyPc modified vitreous carbon electrodes," Journal of Electroanalytical Chemistry, vol. 576, no. 2, pp. 323-332, 2005.

[13] S. Chen, R. D. Webster, C. Talotta, F. Troisi, C. Gaeta, and P. Neri, "Electrochemistry and ion-sensing properties of calix[4]arene derivatives," Electrochimica Acta, vol. 55, no. 23, pp. 7036-7043, 2010.

[14] H. Bingol, E. Kocabas, E. Zor, and A. Coskun, "Spectrophotometric and electrochemical behavior of a novel azocalix [4] arene derivative as a highly selective chromogenic chemosensor for $\mathrm{Cr}^{+3}$," Electrochimica Acta, vol. 56, no. 5, pp. 2057-2061, 2011.

[15] X. Qin, X. Liu, L. Hong-Bo, Y. Li-Na, and H. Xiaoya, "Electrochemical determination of purine and pyrimidine DNA bases based on the recognition properties of azocalix[4]arene," Biosensors and Bioelectronics, vol. 42, pp. 355-361, 2013.

[16] E. Zor, A. O. Saf, and H. Bingol, "Spectrophotometric and voltammetric characterization of a novel selective electroactive chemosensor for $\mathrm{Mg}^{2+}$," Central European Journal of Chemistry, vol. 11, no. 4, pp. 554-560, 2013.

[17] A. J. Bard and H. Lund, Encyclopedia of Electrochemistry of the Elements, vol. 12, Marcel Dekker, New York, NY, USA, 1978.

[18] A. Pailleret, G. Herzog, and D. W. M. Arrigan, "Electrochemical activity of phenolic calixarenes," Electrochemistry Communications, vol. 5, no. 1, pp. 68-72, 2003. 

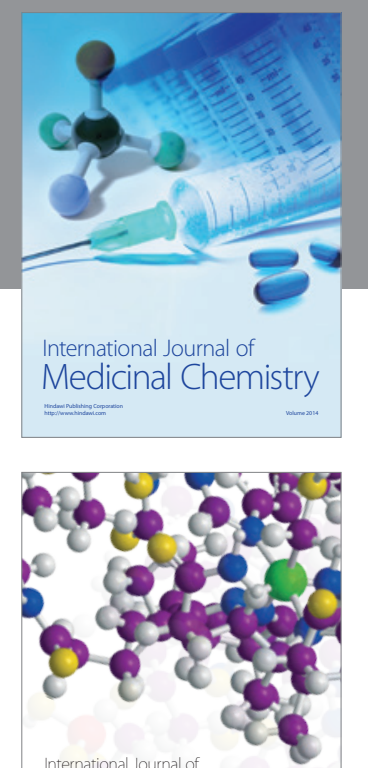

\section{Carbohydrate} Chemistry

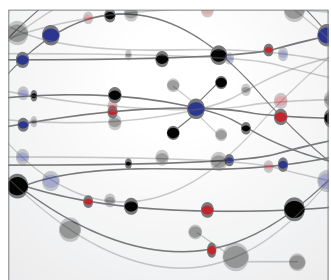

The Scientific World Journal
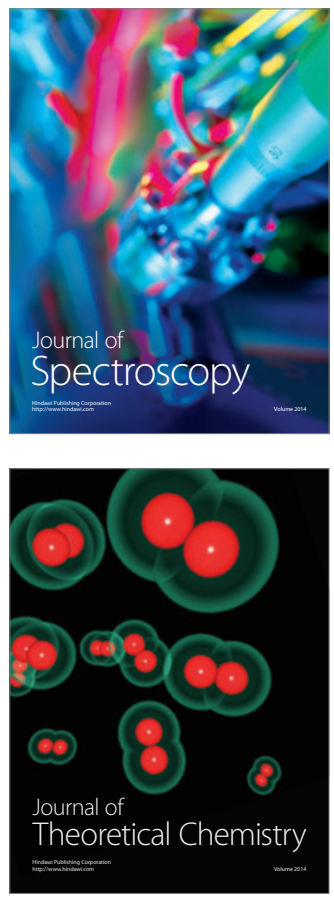


Submit your manuscripts at

http://www.hindawi.com



Analytical Methods

in Chemistry

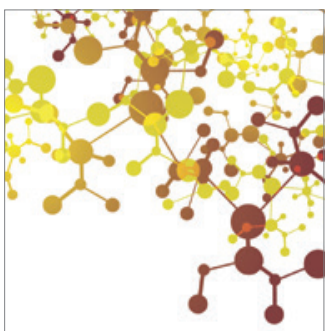

Journal of

Applied Chemistry

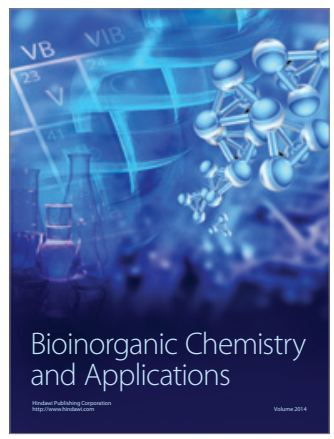

Inorganic Chemistry
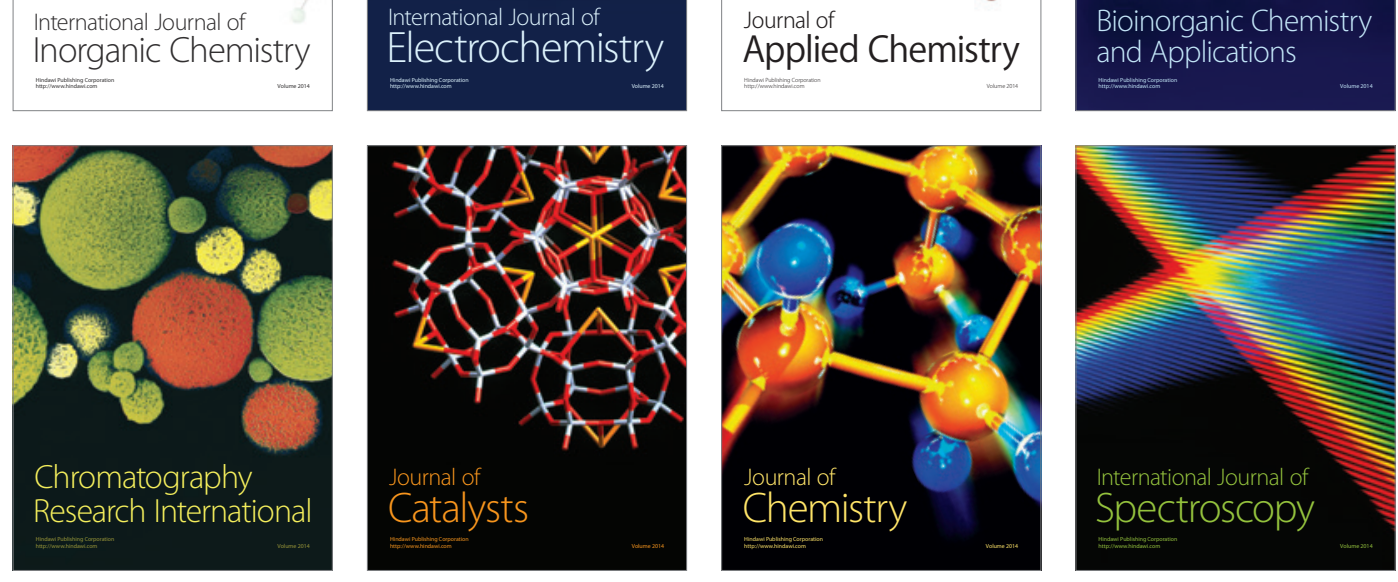